\title{
Condiciones de suelo y vegetación en tres bosques quemados de Nothofagus pumilio en Argentina y experiencias para su restauración activa
}

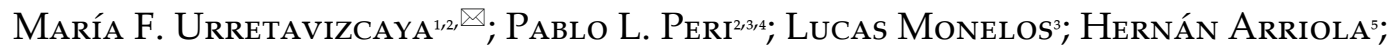 \\ M. Florencia Oyharçabal ${ }^{1}$; Liliana T. Contardi ${ }^{1 / 6}$; Miriam Muñoz; Eduardo \\ SepúlvedA \& Guillermo E. Defossét ${ }^{12,66}$
}

${ }^{1}$ Centro de Investigación y Extensión Forestal Andino Patagónico (CIEFAP). ${ }^{2}$ Consejo Nacional de Investigaciones Científicas y Técnicas de Argentina (CONICET). ${ }^{3}$ Universidad Nacional de la Patagonia Austral (UNPA). ${ }^{4}$ Instituto Nacional de Tecnología Agropecuaria (INTA). ${ }^{5}$ Consejo Agrario Provincial de Santa Cruz (CAP). ${ }^{6}$ Universidad Nacional de la Patagonia San Juan Bosco (UNPSJB).

\begin{abstract}
Resumen. El fuego es un disturbio importante en bosques de lenga de Chubut y Santa Cruz, en la Patagonia argentina. Según del tipo de bosque y la severidad del fuego, el sistema resultante puede diferir en gran medida respecto del original. En este trabajo se evaluaron condiciones post-fuego (vegetación y suelo) que afectarían el restablecimiento de Nothofagus pumilio en tres zonas del gradiente latitudinal de su distribución: La

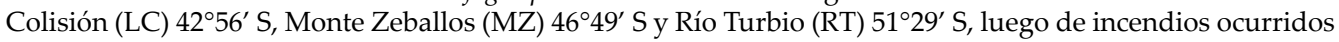
uno, setenta, y veintisiete años atrás, respectivamente. En cada sitio se caracterizó la riqueza de especies y su cobertura en áreas quemadas, y se analizaron 12 propiedades físico-químicas de los primeros $10 \mathrm{~cm}$ del suelo en las áreas quemadas y en las adyacentes no quemadas. En áreas quemadas se realizó la restauración activa estableciendo de plantines de N. pumilio con diferentes dispositivos de protección individual. La cobertura total del suelo fue mayor en RT, la cobertura relativa según hábito y origen de las especies fue diferente entre sitios, mientras que la riqueza y la diversidad fueron similares. Las diferencias en las propiedades del suelo entre áreas quemadas y no quemadas se podrían asociar con la antigüedad del incendio. En todos los sitios, la supervivencia de plantines fue alta $(>70 \%)$ después del primer año, independientemente del tipo de protector, y disminuyó levemente en los años posteriores. En LC, el crecimiento fue mayor en plantines protegidos con tubos de polipropileno. En MZ y RT, el crecimiento fue limitado por el ramoneo de liebres, aun con protectores individuales. En zonas quemadas y con ganado, la herbivoría restringe, e incluso llega a imposibilitar, la regeneración natural de la lenga. La plantación es una alternativa viable si los plantines están protegidos y se realiza algún control de herbivoría por liebres.
\end{abstract}

[Palabras clave: bosques templados, Patagonia, lenga, fuego, riqueza, diversidad, propiedades físico-químicas del suelo, plantación]

\begin{abstract}
Aвstract. Soil and vegetation conditions in three burned Nothofagus pumilio forests in Argentina and experiences for their active restoration. Fire is an important disturbance affecting Nothofagus pumilio (lenga) forests in Chubut and Santa Cruz provinces of Patagonia, Argentina. Depending on the forest structure and the level of fire severity, the resulting stands could substantially differ from the original. In this study, we evaluated post-fire effects on soil and vegetation conditions that might affect reestablishment of lenga plants in three latitudinal areas of its natural distribution in Patagonia: La Colisión (LC) 42 56' S, Monte Zeballos (MZ) $46^{\circ} 49^{\prime} \mathrm{S}$ and Río Turbio (RT) $51^{\circ} 29^{\prime} \mathrm{S}$. The fire events occurred one (LC), seventy (MZ), and twenty-seven (RT) years before treatments establishment, respectively. In each site, we characterized species richness and cover at burned areas, and analyzed 12 physicochemical properties of the first $10 \mathrm{~cm}$ of soil depth at burned and adjacent unburned (control) areas. In burned areas, we performed active restoration experiments by planting lenga seedlings using different protection devices. Soil cover was higher in RT. While plant relative cover according to habit and origin differed between sites, species richness and diversity were similar. Differences in soil physicochemical properties between burned and unburned areas could be associated to the time passed since fire occurrence. At the end of the first growing season, and regardless of the protection device used, survival was high at all sites $(>70 \%)$. This percentage slightly decreased in the subsequent years. In MZ and RT, European hares browsing limited seedling growth. In burned and grazed lenga forests, herbivores restrict the natural regeneration. Restoration by planting lenga seedlings could be a viable alternative by providing protection to hare browsing.
\end{abstract}

[Keywords: temperate forests, Patagonia, lenga, fire, richness and diversity, soil properties, plantation]

Editor asociado: Esteban Jobbágy

$\triangle$ mfurretavizcaya@ciefap.org.ar
Recibido: 23 de noviembre de 2016

Aceptado: 6 de marzo de 2018 


\section{INTRODUCCIÓN}

La restauración ecológica es el proceso de asistencia a la recuperación y el manejo de la integridad ecológica de ecosistemas que fueron degradados, dañados o destruidos (SER 2004). Las metas y líneas de trabajo de la restauración ecológica son variables por su origen complejo y heterogéneo. Una de las líneas deriva de la teoría de la conservación biológica y se centra en la restauración de especies individuales, en especial en el reconocimiento y la preservación de comunidades amenazadas (Ehrenfeld 2000). Si bien esta línea se basa en el conocimiento sobre la autoecología y los requerimientos de hábitat, en las últimas décadas se observó la necesidad de conocer los factores que condicionan la regeneración para avanzar en la restauración de poblaciones y hábitats amenazados (Grubb 1977).

En la Argentina, los bosques templados, también denominados Bosques Subantárticos o Andino Patagónicos (Cabrera 1976), se extienden desde el norte de la provincia de Neuquén (a la altura del paralelo $35^{\circ} \mathrm{S}$ ) hasta la Isla de los Estados (paralelo $54^{\circ} \mathrm{S}$ ). Se extienden en una franja de $2000 \mathrm{~km}$ de longitud, con ancho máximo de $75 \mathrm{~km}, \mathrm{y}$ cubren $\sim 3.73$ millones de hectáreas (CIEFAP and MAyDS 2016), lo que representa sólo $5 \%$ de la superficie de la región. Una especie destacada en estos bosques es la lenga (Nothofagus pumilio [Poepp. et Endl.] Krasser) debido a su rango de distribución latitudinal, a la superficie de ocupación y a la calidad de su madera. La lenga no sólo tiene un valor productivo significativo, sino que, además, dada la ubicación de sus bosques, cumple con funciones clave de protección y conservación. Los bosques de lenga en la Argentina ( 1.68 millones de hectáreas) forman, en la mayoría de los casos, el último estrato arbóreo en altitud y protegen casi la totalidad de las cabeceras de cuencas de agua dulce de la Patagonia.

La provincia de Chubut cuenta con $743 \mathrm{mil}$ hectáreas de bosques nativos, de las cuales 400 mil corresponden a bosques de lenga. Se estima que $20 \%$ del total de bosques y $44 \%$ de las 130 mil ha de bosque alto de producción se encuentra degradado (Bava et al. 2006). La provincia de Santa Cruz cuenta con aproximadamente 400 mil hectáreas de bosques nativos, correspondiendo más de 230 mil a bosques de lenga (CIEFAP and MAyDS 2016). Se estima que el $24 \%$ de los mismos se encuentra degradado (Peri and Ormaechea 2013b).En estos bosques los factores de disturbio más importantes son el fuego y la herbivoría. El fuego produce efectos directos e indirectos que condicionan los procesos de regeneración de la especie, y según el tipo de bosque considerado, el sistema resultante luego de producido el disturbio puede diferir sustancialmente del original (Rusch 1989; Kitzberger et al. 2005a).

El principal factor que limita el restablecimiento de la lenga luego del fuego es la ausencia de árboles adultos vivos. Dada la alta sensibilidad de las copas de lenga a la temperatura, los incendios severos pueden no dejar árboles remanentes en cientos de hectáreas. Es por ello que se observa que superficies extensas antes cubiertas por bosques de lenga se transformaron en arbustales, cañaverales o pastizales (Kitzberger et al. 2005b). Asimismo, la muerte del dosel influye de forma negativa en la disponibilidad de agua en el suelo, y las condiciones climáticas prevalentes en Patagonia, como fuertes y desecantes vientos del oeste, tampoco propician la regeneración de la lenga en espacios grandes y abiertos por los incendios (Kalela 1941). Otro de los factores de impacto desfavorable para el proceso de regeneración del bosque post-fuego es la introducción de ganado, especialmente si la carga animal es elevada (Peri 2003). La herbivoría, tanto de ganado doméstico (ovino, bovino) como de pequeños herbívoros (liebres), afecta de manera negativa la supervivencia de plántulas, y su efecto se intensifica en bosques abiertos por fuegos severos (Kitzberger et al. 2005b). Asimismo, en zonas que fueron libradas al pastoreo se puede producir el proceso de "empastado", que consiste en la formación de una capa de vegetación herbácea con un denso sistema radical superficial, que puede impedir el establecimiento de la regeneración (Rusch 1987; Quinteros 2014).

Para bosques de lenga del noroeste de la Patagonia argentina afectados por fuegos intensos en pequeños parches se ha sugerido que la productividad post-fuego y la regeneración estarían relacionadas con los cambios edáficos, en especial aquellos que afectan la dinámica del nitrógeno y el agua (Alauzis et al. 2004). No obstante, estudios posteriores en la misma área sugieren la desaparición de ese efecto con el paso del tiempo (Kitzberger et al. 2005a). En coincidencia con lo anterior, se indica que la baja regeneración a 7-8 años del fuego se relacionaría más con la intensidad del fuego y con el exiguo banco de semillas que con 
la fertilidad del suelo (Varela et al. 2006). A largo plazo, la retroalimentación positiva entre los cambios que produce el fuego en el hábitat y la herbivoría puede conducir de forma gradual, ecosistemas boscosos hacia comunidades estructuralmente más abiertas, como arbustales o pastizales (Veblen et al. 1996). Por consiguiente, es necesario avanzar en el conocimiento del efecto del fuego sobre el suelo y los distintos componentes del ecosistema de los bosques quemados a fin de evaluar su resiliencia y planificar su manejo y restauración. En la región, las experiencias sobre restauración activa de bosques de lenga son ciertamente escasas, por lo que es importante abordar esta temática para poder definir lineamientos de intervención.

El objetivo de este trabajo es evaluar las condiciones post-fuego de vegetación y suelo que podrían afectar el establecimiento de lenga, en tres zonas ubicadas en un gradiente latitudinal de su distribución en la Argentina, y con distinta antigüedad del disturbio fuego. Para ello se caracteriza la riqueza de especies y la cobertura del suelo de los tres sitios, se analizan los cambios en las principales propiedades físico-químicas del suelo de los bosques quemados en comparación con los no quemados, y se implementan técnicas de restauración activa. Además, y considerando la evidencia empírica del efecto negativo de pequeños herbívoros en el restablecimiento de la especie, se prueban distintos dispositivos de protección.

\section{Materiales y Métodos}

\section{Área de estudio}

El estudio se realizó en tres áreas ubicadas en un gradiente latitudinal que abarca un rango de $8^{\circ}$ de la distribución de lenga en la Argentina en las zonas de Esquel (Provincia de Chubut), y Los Antiguos y Río Turbio (Provincia de Santa Cruz). En cada zona geográfica se seleccionó un área de estudio afectada por fuego de alta severidad y se ubicaron sitios a una distancia aproximada de $1000 \mathrm{~m}$ del borde del bosque sin quemar, donde la probabilidad de arribo de semillas de lenga mediante dispersión anemócora es muy baja. En los tres sitios se estableció una unidad de estudio de 100x100 m (1 ha) que fue clausurada al ingreso de ganado doméstico. Los sitios de norte a sur son LC: La Colisión (42 $\left.56^{\circ} \mathrm{S}-7^{\circ} 30^{\prime} \mathrm{O}\right)$, próximo a la ciudad de Esquel, quemado en 2008; MZ: Monte Zeballos $\left(46^{\circ} 49^{\prime} \mathrm{S}-71^{\circ} 54^{\prime} \mathrm{O}\right)$, próximo a la localidad de Los Antiguos, quemado en 1941, y RT: Río Turbio $\left(51^{\circ} 29^{\prime} \mathrm{S}-72^{\circ} 19^{\prime} \mathrm{O}\right)$, cercano a la ciudad homónima, quemado en 1983.

El área de estudio La Colisión se encuentra ubicada a media ladera con exposición sur a 1000 m. s. n. m. Su temperatura media máxima anual (TMMaxA) es $14.3^{\circ} \mathrm{C}$ y su temperatura media mínima anual (TMMinA) es $2.7^{\circ} \mathrm{C}$. La precipitación media anual (PMA) es $488 \mathrm{~mm}$. Luego del incendio, esta área no tuvo uso pastoril (Figura 1, arriba). Monte Zeballos se ubica también a media ladera con exposición noreste a $850 \mathrm{~m} \mathrm{s.} \mathrm{n.} \mathrm{m.} \mathrm{Su} \mathrm{TMMaxA} \mathrm{es} 14.0$ ${ }^{\circ} \mathrm{C}$, su TMMinA es $3.6^{\circ} \mathrm{C}$ y su PMA es $216 \mathrm{~mm}$. Luego del incendio fue utilizado para pastoreo de ganado ovino (Figura 1, centro). El área de Río Turbio se ubica en una zona plana a $450 \mathrm{~m}$ s. n. m. Su TMMaxA es $10.9^{\circ} \mathrm{C}$, su TMMinAes $0.7^{\circ} \mathrm{C}$ y su PMA es $442 \mathrm{~mm}$. Con posterioridad al incendio fue utilizada para ganado vacuno (Figura 1, abajo). Los datos climáticos corresponden a las estaciones meteorológicas más cercanas a los sitios (Para LC, la Estación del Servicio Meteorológico Nacional (SMN) del Aeropuerto de Esquel; para MZ, la estación del INTA en Los Antiguos; para RT, la estación del SMN de Río Turbio). La Colisión y Monte Zeballos son sitios que tienen un régimen de precipitación de tipo mediterráneo, caracterizado por la concentración de la precipitación en el semestre frío, mientras que Río Turbio tiene un régimen isohigro, con precipitaciones que se distribuyen de forma más o menos uniforme a lo largo del año. Las estaciones cercanas a La Colisión y Monte Zeballos están ubicadas hacia el este y a menor altitud que los sitios de estudio a los cuales refieren, por lo que se estima que la precipitación en los mismos puede ser superior respecto de los valores indicados. La selección de sitios con distinta exposición y posición en la ladera puede influir en los resultados de las variables a analizar, principalmente por las diferencias en la radiación que reciben los mismos, lo cual afecta de forma directa a otras variables como la temperatura y la humedad del suelo.

En ninguno de los sitios se extrajo la madera quemada luego del fuego. La Colisión presenta árboles quemados tanto en pie como caídos, en Monte Zeballos se observan restos de troncos quemados muy degradados y en Río Turbio hay presencia de troncos en el suelo (Figura 1). Las tres áreas se ubican hacia el límite este de la distribución de la especie en la Argentina, y representan condiciones ambientales secas de la misma (López Bernal et al. 2012). 



Figura 1. Imágenes de los sitios de estudio en el gradiente latitudinal de norte a sur en la Patagonia Argentina (La Colisión, Monte Zeballos y Río Turbio). A la izquierda, imágenes de los bosques sin quemar; a la derecha, de los bosques quemados.

Figure 1. Photographs of the study sites located in the North to South latitudinal gradient in Argentine Patagonia (La Colisión, Monte Zeballos and Río Turbio). Figures on the left, undisturbed lenga forests; figures in the right, nearby burned forests

\section{Caracterización de las condiciones ambientales}

Riqueza y cobertura del suelo. En 2009, se establecieron 10 unidades experimentales (parcelas) de $16 \mathrm{~m}^{2}$ en cada área de estudio, donde se describió la vegetación presente. Para la ubicación de las parcelas se dividió cada área de estudio (clausura) en 10 fajas de 10 metros, y cada faja se dividió en 10 unidades, resultando en cuadros de 10×10 m. Luego, se seleccionó un cuadro al azar dentro de cada faja y en su centro se instaló una parcela de $4 \times 4 \mathrm{~m}$. En cada parcela se registró la totalidad de las plantas vasculares presentes y se estimó visualmente su cobertura. Las especies fueron determinadas según Correa (1969-1988) y Zuloaga et al. (2009). Se estimó también la proporción de cobertura de suelo ocupada por los troncos caídos y el suelo descubierto.

Propiedades del suelo. Dentro de cada unidad de estudio, y en zonas próximas de bosque verde sin disturbio de fuego, en octubre de 2009 se tomaron tres muestras de suelo compuestas de los primeros $10 \mathrm{~cm}(\sim 500 \mathrm{~g})$. En el Laboratorio de Suelos de la UNPSJB-CIEFAP se determinaron las siguientes propiedades físico-químicas: análisis granulométrico (textura), $\mathrm{pH}$ en Fna, $\mathrm{pH}$ actual (suelo: agua de 1:1), conductividad eléctrica (suelo:agua 
de 1:5), materia orgánica (Davies 1974), nitrógeno total (método de Kjeldahl) (Bremner 1960), fósforo disponible (método Kurtz № 1) (Bray and Kurtz 1945), azufre inorgánico extractable (adsorbido+soluble) (método turbidimétrico), capacidad de intercambio catiónico (Richter et al. 1982), extracción de bases de intercambio (Schollenberger and Simon 1945), determinación de calcio y magnesio (Richter et al. 1982) y determinación de sodio y potasio (Black 1965).

\section{Ensayos de restauración activa}

En cada área de estudio se establecieron ensayos de restauración activa mediante plantación. En 2009 se plantó en La Colisión y Río Turbio, y en el 2010, en Monte Zeballos y nuevamente en Río Turbio. En todos los ensayos, los plantines fueron protegidos con dispositivos individuales, de entre 50 y $60 \mathrm{~cm}$ de altura, para evaluar su eficacia contra el daño de pequeños herbívoros, en particular de la liebre europea (Lepus europaeus). En el ensayo La Colisión 2009 se utilizaron dos tipos de dispositivos de protección, en Monte Zeballos 2010 tres y en Río Turbio 2009 uno. El ensayo instalado en Río Turbio en 2010 se estableció para evaluar el efecto de tres dispositivos de protección en ese sitio.

La Colisión. En otoño de 2009 se estableció un ensayo de plantación con plantines de dos años de edad cultivados mediante el sistema mixto de producción (Quiroz et al. 2009) en un Vivero de Esquel, a partir de semilla proveniente de la Reserva Provincial Lago Guacho en Chubut $\left(43^{\circ} 49^{\prime} 43^{\prime \prime} \mathrm{S}-71^{\circ} 26^{\prime} 45^{\prime \prime}\right.$ O). Se utilizaron 384 plantines, ubicados a $2 \times 2 \mathrm{~m}$, en 16 filas de 24 lengas cada una. El diámetro de cuello y la altura de los plantines fueron, en promedio, $6.3 \mathrm{~mm}$ y $37.5 \mathrm{~cm}$, respectivamente. Todas las lengas fueron protegidas con dispositivos individuales para prevenir el daño por pequeños herbívoros. Se utilizaron protecciones de malla metálica de 50 cm de altura (MM) y tubos de polipropileno de $60 \mathrm{~cm}$ de altura (TP), colocando dos filas del mismo tipo de protector en forma alternada (Figura 2).

Monte Zeballos. En otoño de 2010 se estableció un ensayo con plantines de 3 años, del mismo lote que los utilizados en $\mathrm{La}$ Colisión en 2009, pero trasvasados a bolsas de polietileno donde permanecieron durante la tercera estación de crecimiento. Se utilizaron 352 plantines, ubicados a $2 \times 2$, en 16 filas de 22 lengas cada una. El diámetro de cuello y la altura fueron, en promedio, $7.3 \mathrm{~mm}$ y 37.1 $\mathrm{cm}$, respectivamente. Todas las lengas fueron protegidas con dispositivos individuales para prevenir el daño por pequeños herbívoros. Se utilizaron protecciones de malla metálica (MM) y tubos de polipropileno (TP) como en La Colisión, y también de malla plástica de color verde de $60 \mathrm{~cm}$ de altura (MP), colocando dos filas del mismo tipo de protector en forma alternada (Figura 3).

Río Turbio. En otoño de 2009 se estableció un ensayo con plantines de dos años de edad, del mismo lote de los utilizados en La Colisión. La plantación de 352 lengas también se realizó a un distanciamiento de $2 \times 2 \mathrm{~m}$, en 16 filas de 22 plantines cada una. El diámetro de cuello y la altura de los plantines fueron, en promedio, $6.3 \mathrm{~mm}$ y $37.5 \mathrm{~cm}$, respectivamente. A todos los plantines de este ensayo se los protegió con una malla plástica verde de $60 \mathrm{~cm}$ de altura (Figura 4A).

En otoño de 2010 se estableció un ensayo con plantines de tres años producidos en un
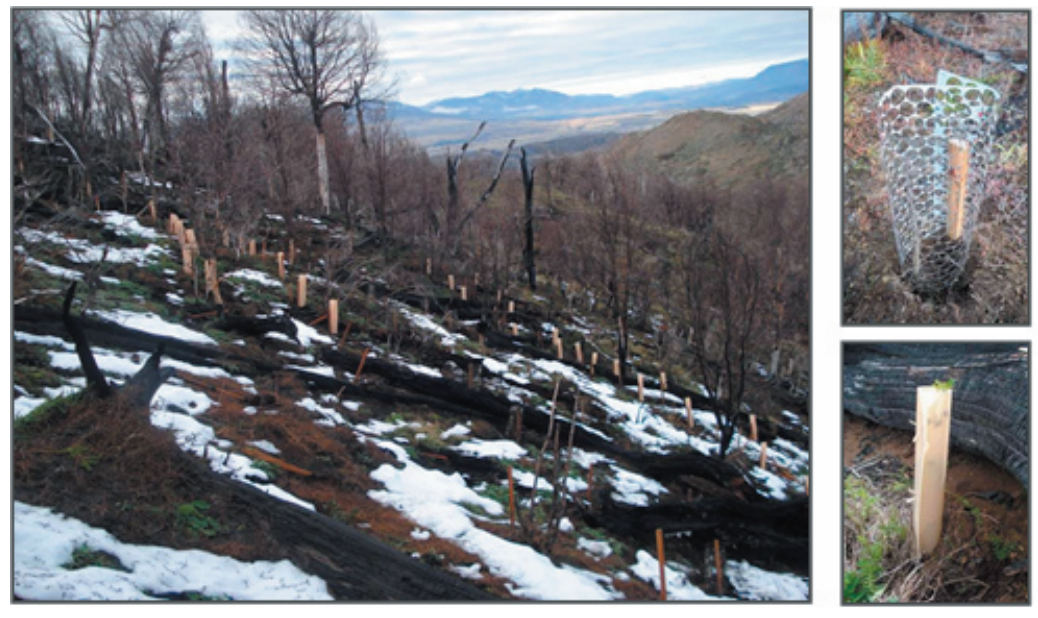

Figura 2. Imagen del sitio de plantación en La Colisión (izquierda) y de los dispositivos utilizados: malla metálica (derecha arriba) y tubo de polipropileno (derecha abajo).

Figure 2. Photograph of La Colisión plantation site (left) showing the protection devices used: metallic mesh (up right) and polypropylene tube (bottom right). 


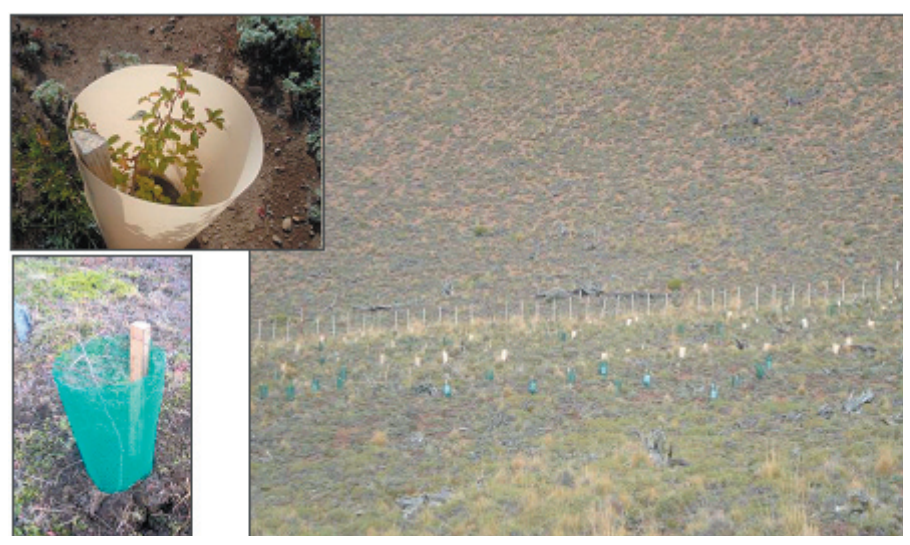

Figura 3. Imagen del sitio de plantación en Monte Zeballos (derecha) y de los dispositivos utilizados: tubo de polipropileno (izquierda arriba) y malla plástica (izquierda abajo).

Figure 3. Photograph of Monte Zeballos plantation site (left) and of the protection devices used: metallic mesh (up left) and polypropylene tube (bottom left). vivero de Trevelin, Chubut, también mediante el sistema mixto, con semilla procedente de la misma reserva que los anteriores. Se utilizaron 252 plantines, ubicados a 2x2, en seis filas de 42 lengas cada una. Los plantines presentaban, en promedio, un diámetro de cuello $12.5 \mathrm{~mm}$ y $65 \mathrm{~cm}$ de altura. Los plantines se protegieron con malla plástica, malla metálica y tubos de polipropileno, y también se dejaron plantines sin protección (Figura 4B).

Mediciones. A todos los plantines se les midió la altura inmediatamente después de la plantación. Al finalizar la primera estación de crecimiento de cada ensayo se registró supervivencia, altura alcanzada y presencia de daños o ápice seco. En los años siguientes la evaluación de supervivencia y altura varió

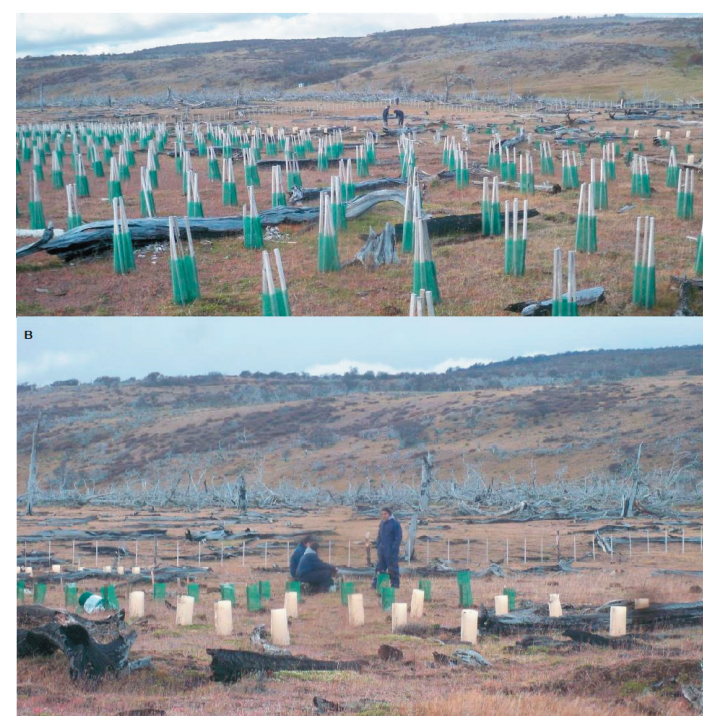

Figura 4. Imagen del sitio y ensayos de plantación en Río Turbio 2009 (A) y 2010 (B).

Figure 4. Photograph of Río Turbio plantation site in 2009 (A) and 2010 (B). entre los sitios. En LC 2009 se efectuó al 2oㅜ $3^{\circ}$ y $4^{\circ}$ año, en MZ 2010 al $4^{\circ}$ año, en RT 2009 al $2^{\mathrm{o}}, 3^{\mathrm{o}}$ y $5^{\mathrm{o}}$ año, y en RT 2010 al $2^{\circ}$ y $4^{\underline{o}}$ año.

\section{Análisis}

Para cada sitio se construyó la curva de acumulación de especies basada en la presencia/ausencia de especies vasculares superiores, mediante el uso de riqueza y Chao2 en el software EstimateS 9.1 (Colwell 2013). Este ajuste sirve para validar el esfuerzo de muestreo para cubrir toda la gama de especies vasculares presentes en las parcelas al estimar el porcentaje de especies registradas (Jiménez-Valverde and Hortal 2003; Silva et al. 2017). Las especies registradas se clasificaron por hábito como herbáceas, gramíneas o graminoides, arbustivas y arbóreas, y por estatus como nativas o endémicas y exóticas o naturalizadas, según Zuloaga et al. (2009). Se realizó un análisis de componentes principales utilizando como variables la cobertura de las especies registradas en los tres sitios. Para evaluar diferencias entre sitios respecto de la cobertura total y de la cobertura relativa según el tipo de hábito y origen se utilizó análisis de la varianza (ANAVA). Con anterioridad al análisis se evaluaron los supuestos de homogeneidad de varianza y de normalidad. La riqueza de especies y el índice de diversidad de Shannon-Wiener también se compararon entre sitios mediante ANAVA. Para la separación de medias se utilizó la prueba de Fisher de diferencias mínimas significativas. Para el análisis y la comparación de medias de las variables entre sitios, se consideró a cada sitio como una población y a cada unidad de muestreo dentro de ella como una repetición. De esta manera se asumió que el error de muestreo representa el error experimental, dado que en este tipo de trabajos de investigación ecológica aplicada, las unidades de muestreo no constituyen 
verdaderas repeticiones (Hurlbert 1984), por lo cual los resultados no son directamente extrapolables a otras áreas.

Para evaluar si existían diferencias en las propiedades del suelo entre las zonas quemadas respecto de las no quemadas se utilizó ANAVA para cada una de las variables estudiadas. Considerando la diferencia de antigüedad de fuego entre los sitios, el análisis se realizó independientemente para cada lugar. Antes de realizar el análisis se evaluaron los supuestos de homogeneidad de varianza y de normalidad. Los valores de nitrógeno, calcio y sodio fueron transformados para cumplir con los supuestos del análisis.

La supervivencia se evaluó en todas las plantaciones al primer año y también al $2^{\circ}, 3^{\circ}$ y $4^{\circ}$ año en LC, al $4^{\circ}$ año en $\mathrm{MZ}$, al $2^{\circ}, 3^{\circ}$ y $5^{\circ}$ año en RT 2009 y al $2^{\circ}$ y $4^{\circ}$ año en RT 2010. En las plantaciones con dos o más dispositivos de protección se evaluó el efecto de los mismos mediante cuadros de contingencia.

La altura alcanzada y el efecto del tipo de protector se evaluaron mediante ANAVA en LC 2009 y en MZ y RT 2010. Cuando se obtuvieron diferencias significativas se aplicó la prueba de Tukey para la separación de medias. A fin de conocer si la supervivencia se asociaba a las variables de suelo y de cobertura estudiadas previamente, se realizó un análisis de correlación entre las propiedades del suelo, la cobertura total y relativa, y el porcentaje de supervivencia al primer año en los tres sitios.

\section{Resultados}

\section{Riqueza y cobertura del suelo}

Se identificó un total de 41 especies en los tres sitios, de las cuales 29 (71\%) son nativas o endémicas y 12 (29\%) exóticas o naturalizadas. Respecto del hábito, 10 especies (24\%) son arbustivas, $25(61 \%)$ son hierbas, 5 (12\%) gramíneas, y 1 (2\%) arbórea. Sólo 6 especies (5 nativas y 1 exótica) se registraron en dos sitios (LC y MZ) (Tabla $1)$. Los coeficientes de determinación $\left(R^{2}\right)$ de las curvas de acumulación de los sitios (LC, MZ y RT: 0.99), indican un buen ajuste del modelo utilizado. Los parámetros derivados de las curvas de acumulación permitieron corroborar que el conjunto de especies fue muestreado satisfactoriamente. La proporción de especies registradas fue $80 \%$ en LC, $94 \%$ en MZ y $92 \%$ en RT.
La mayoría de las especies presentaron valores de cobertura media menor a 10\% (Tabla 1). Las especies que mostraron coberturas más altas fueron Vicia magellanica $(24.3 \%)$, Phacelia secunda (12.3\%) y Muehlembeckia hastulata (10.8\%) en LC; Mulinum spinosum (25.6\%), Acaena splendens (16.7\%) y Stipa sp. (10.5\%) en MZ; Hieracium praealtum (42.7\%), Baccharis magellanica $(21.5 \%)$ y Agrostis perennans (12.1\%) en RT. La especie arbórea dominante, N. pumilio, fue registrada sólo en $\mathrm{MZ}$ y con muy baja cobertura. El porcentaje de suelo descubierto fue $35.5 \pm 5.8 \%$ en LC, $19.8 \pm 6.1 \%$ en $\mathrm{MZ}$ y $<1 \%$ en RT. En este último sitio se observó $7.4 \pm 2.1 \%$ del suelo cubierto por musgo. Los troncos caídos en LC ocuparon $12.5 \pm 3.2 \%$, mientras que en MZ y RT ocuparon menos de $10 \%$. Los dos primeros ejes del ACP muestran el ordenamiento del conjunto de todas las especies relevadas sólo en función de su cobertura (Figura 5). Sin bien el porcentaje de la variabilidad explicada por los dos primeros ejes es bajo $(<40 \%)$, se observa claramente el agrupamiento de las especies por sitio debido a la baja similitud entre ellos.

La cobertura total y la cobertura relativa según el hábito de las especies y su origen fue significativamente diferente entre sitios $(P<0.01)$. La mayor cobertura total se registró en RT (Tabla 2). La cobertura de especies arbustivas fue superior en $\mathrm{MZ}$ respecto de LC y RT, que no se diferenciaron entre sí. La cobertura de especies gramíneas fue similar en RT y MZ; ambas fueron superiores a la de LC. Inversamente, la cobertura de especies herbáceas fue superior en LC respecto de MZ y RT; éstas últimas no se diferenciaron entre sí. Respecto del origen de las especies, en LC y MZ, más del 90\% de la cobertura corresponde a especies nativas, un valor significativamente superior a RT, donde se registró el 51\% de cobertura de estas especies. En cuanto a riqueza y diversidad, los sitios no se diferenciaron entre sí (Tabla 2).

\section{Propiedades físico-químicas de los suelos}

La textura del suelo de las zonas de bosque no quemado o verde, en los tres sitios de estudio, resultó franco-arenosa. En las zonas quemadas (clausuras), la textura fue franco arenosa para LC y MZ, y franca en RT. Las propiedades físico-químicas de los suelos no quemados de LC y MZ son características de los suelos formados a partir de depósitos de cenizas volcánicas. Ambos sitios presentan valores de pHFNa superiores a 9.2, lo cual indica la presencia de alófano e imogolita; 
Tabla 1. Listado de especies registradas, abreviatura (Abr.), tipo de hábito $(\mathrm{H})$ y cobertura promedio ( $\pm \mathrm{EE})$ en los tres sitios de estudio ( $n=10$ por sitio). Tipo de hábito según Zuloaga et al. (2009): h=herbáceo, g=gramínea o graminoide, a=arbustivo, y A=arbóreo. Los nombres abreviados de las especies (Abr.) se utilizaron en el ACP. * Géneros o especies exóticas o naturalizadas. \# Especies con coberturas mayores a 10\%.

Table 1. List of recorded species (Especie), their abbreviation (Abr.), growth form $(\mathrm{H})$, and mean cover $( \pm \mathrm{SE})$ found in the three study sites ( $\mathrm{n}=10$ per site). Growth form was defined according to Zuloaga et al. (2009): h=herbaceous, $\mathrm{g}=$ grass or grass-like species, a=shrubs, and A=trees. Species abbreviations (Abr.) were used in the PCA analysis. ${ }^{*}$ Exotic or naturalized genus and species. \# Species whose cover is higher than $10 \%$.

\begin{tabular}{|c|c|c|c|c|c|}
\hline Especie & Abr. & $\mathrm{H}$ & La Colisión & Monte Zeballos & Río Turbio \\
\hline Acaena antarctica & AcAn & $\mathrm{h}$ & & & $2.1 \pm 0.8$ \\
\hline Acaena pinnatifida & $\mathrm{AcPi}$ & $\mathrm{h}$ & $0.6 \pm 0.4$ & $2.2 \pm 0.9$ & \\
\hline Acaena splendens \# & AcSp & $\mathrm{h}$ & $1.6 \pm 1.0$ & $16.7 \pm 4.4$ & \\
\hline Agrostis perennans *\# & $\mathrm{AgPe}$ & $\mathrm{g}$ & & & $12.1 \pm 4.1$ \\
\hline Anemone multiflora & $\mathrm{AnMu}$ & $\mathrm{h}$ & & $2.2 \pm 0.9$ & \\
\hline Baccharis magellanica \# & BaMa & $\mathrm{a}$ & & & $21.5 \pm 5.7$ \\
\hline Berberis microphylla & BeMi & $\mathrm{a}$ & $1.5 \pm 0.8$ & $9.4 \pm 3.2$ & \\
\hline Berberis serratodentata & BeSe & $\mathrm{a}$ & $0.8 \pm 0.6$ & & \\
\hline Calceolaria sp. & CaSp & $\mathrm{h}$ & $0.6 \pm 0.4$ & & \\
\hline Carduus thoermeri* & CaTh & $\mathrm{h}$ & $0.2 \pm 0.1$ & & \\
\hline Cerastium arvense & CeAr & $\mathrm{h}$ & & $1.1 \pm 0.4$ & \\
\hline Circium vulgare* & $\mathrm{CiVu}$ & $\mathrm{h}$ & $0.7 \pm 0.4$ & & \\
\hline Elymus angulatus & ElAn & $\mathrm{g}$ & $1.0 \pm 1.0$ & & \\
\hline Erigerom patagonicus & $\mathrm{ErPa}$ & $\mathrm{h}$ & & $1.1 \pm 0.7$ & \\
\hline Galium aparine* & GaAp & $\mathrm{h}$ & $3.4 \pm 1.2$ & & \\
\hline Gamochaeta nivalis & $\mathrm{GaNi}$ & $\mathrm{h}$ & & & $3.4 \pm 0.7$ \\
\hline Geranium magellanicum & GeMa & $\mathrm{h}$ & $2.5 \pm 1.0$ & & \\
\hline Hieracium glaucifolium *\# & HiGl & $\mathrm{h}$ & & & $42.7 \pm 6.0$ \\
\hline Hypochoeris sp. ${ }^{*}$ & HySp & $\mathrm{h}$ & & $0.6 \pm 0.6$ & \\
\hline Leucheria sp. & LeSp & $\mathrm{h}$ & $0.7 \pm 0.4$ & $0.6 \pm 0.6$ & \\
\hline Luzula chilensis & $\mathrm{LuCh}$ & $\mathrm{g}$ & & & $3.2 \pm 1.1$ \\
\hline Muehlenbeckia hastulata \# & $\mathrm{MuHa}$ & $\mathrm{a}$ & $10.8 \pm 2.4$ & & \\
\hline Mulinum spinosum \# & MuSp & $\mathrm{a}$ & & $25.6 \pm 6.4$ & \\
\hline Nothofagus pumilio & $\mathrm{NoPu}$ & A & & $1.1 \pm 0.7$ & \\
\hline Phacelia secunda \# & PhSe & $\mathrm{h}$ & $12.3 \pm 3.0$ & & \\
\hline Poa pratensis * & PoPr & $\mathrm{g}$ & & & $5.2 \pm 2.1$ \\
\hline Ribes cucullatum & $\mathrm{RiCu}$ & $\mathrm{a}$ & $0.2 \pm 0.1$ & $1.1 \pm 0.7$ & \\
\hline Ribes magellanicum & RiMa & $\mathrm{a}$ & $1.1 \pm 0.6$ & & \\
\hline Rumex acetosella* & RuAc & $\mathrm{h}$ & $1.6 \pm 0.5$ & $2.8 \pm 0.9$ & \\
\hline Schinus patagonicus & $\mathrm{ShPa}$ & $\mathrm{a}$ & $0.2 \pm 0.1$ & & \\
\hline Senecio neaei & $\mathrm{SeNe}$ & $\mathrm{a}$ & & $0.6 \pm 0.5$ & \\
\hline Senecio trifurcatus & SeTr & $\mathrm{a}$ & & & $1.2 \pm 0.5$ \\
\hline Stipa sp.\# & StSp & $\mathrm{g}$ & & $10.5 \pm 2.8$ & \\
\hline Sisyrinchium sp. & SySp & $\mathrm{h}$ & & $1.1 \pm 0.7$ & \\
\hline Taraxacum officinale * & $\mathrm{TaOf}$ & $\mathrm{h}$ & & $3.3 \pm 0.8$ & \\
\hline Trifolium repens* & TrRe & $\mathrm{h}$ & & & $0.7 \pm 0.5$ \\
\hline Ugni molinae* & UGMo & $\mathrm{h}$ & $1.6 \pm 1.0$ & & \\
\hline Verbascum thapsus * & VeTh & $\mathrm{h}$ & $0.6 \pm 0.4$ & & \\
\hline Vicia magellanica \# & VicMa & $\mathrm{h}$ & $24.3 \pm 5.0$ & & \\
\hline Viola maculata & ViMa & $\mathrm{h}$ & $0.3 \pm 0.3$ & & \\
\hline Viola sp. & ViSp & $\mathrm{h}$ & & $1.1 \pm 0.7$ & \\
\hline
\end{tabular}

en cambio, Río Turbio presenta un valor de pHFNa igual a 8.4, lo que señala presencia de haloisita. Teniendo en cuenta los valores de las propiedades analizadas, la fertilidad de los sitios con bosque sería mayor en LC, intermedia en RT y menor en MZ.
En LC, a más de un año de la ocurrencia del fuego, se detectaron diferencias en la mayoría de las variables estudiadas entre la zona quemada y la no quemada o bosque verde (Tabla 3). Entre ellas, la conductividad eléctrica, el carbono, el nitrógeno, el fósforo, 
Tabla 2. Valores medios $( \pm \mathrm{EE}$ ) de la cobertura total del suelo (Cobertura total) y relativa por hábitat y origen, riqueza (S) y diversidad (índice de Shannon, H) en los tres sitios de estudio. Letras diferentes indican diferencias significativas entre sitios $(\mathrm{P}<0.05)$

Table 2. Mean values $( \pm S E)$ of total (Cobertura total) and relative cover (Cobertura relativa), according to habitat and origin, species richness (S) and diversity (Shannon index, $\mathrm{H}$ ) in the three study sites. Different lower-case letters indicate significant differences among sites $(\mathrm{P}<0.05)$.

\begin{tabular}{ccccccccc}
\hline \multirow{2}{*}{ Sitio } & \multirow{2}{*}{$\begin{array}{c}\text { Cobertura } \\
\text { total }\end{array}$} & Arbustos & Gramíneas & Hierbas & Exóticas & Nativas & S & $\mathrm{H}$ \\
\hline La Colisión & $66.6 \pm 9 \mathrm{a}$ & $22.4 \pm 4.1 \mathrm{a}$ & $0.9 \pm 0.9 \mathrm{a}$ & $76.7 \pm 3.9 \mathrm{~b}$ & $9.1 \pm 1.6 \mathrm{a}$ & $90.9 \pm 1.6 \mathrm{~b}$ & $7.9 \mathrm{a}$ & $1.54 \mathrm{a}$ \\
Monte Zeballos & $80.5 \pm 9 \mathrm{a}$ & $43.4 \pm 8.5 \mathrm{~b}$ & $15.2 \pm 3.9 \mathrm{~b}$ & $40.8 \pm 7.2 \mathrm{a}$ & $8.7 \pm 1.6 \mathrm{a}$ & $91.2 \pm 1.6 \mathrm{~b}$ & $7.3 \mathrm{a}$ & $1.61 \mathrm{a}$ \\
Río Turbio & $99.5 \pm 1 \mathrm{~b}$ & $22.9 \pm 5.7 \mathrm{a}$ & $20.5 \pm 6.1 \mathrm{~b}$ & $49.0 \pm 5.5 \mathrm{a}$ & $48.7 \pm 5.1 \mathrm{~b}$ & $51.3 \pm 5.1 \mathrm{~b}$ & $6.6 \mathrm{a}$ & $1.24 \mathrm{a}$ \\
\hline
\end{tabular}

el calcio y el potasio disminuyeron $(P<0.05)$ en el quemado, mientras que el sodio disminuyó marginalmente $(P=0.08)$. En contraste, el $\mathrm{pH}$, el magnesio y el azufre fueron mayores en el quemado $(P<0.05)$. En RT, a 27 años del fuego, la conductividad eléctrica, el magnesio y el azufre presentaron mayores $(P<0.05)$ valores en el quemado, y el fósforo presentó la tendencia de ser mayor en el bosque no quemado $(P=0.06)$. En $\mathrm{MZ}$, a casi 70 años del fuego, sólo el sodio presentó diferencias, y fue mayor en el bosque no quemado (Tabla 3).

\section{Ensayos de restauración activa}

La Colisión. La supervivencia promedio de los plantines en otoño de 2010, luego de la primera estación de crecimiento, fue $72 \%$ y no se detectaron diferencias respecto del tipo de protector usado. Sí, en cambio, se observó una mejor vitalidad y mayor altura $(P<0.05)$ en las plantas que tenían tubo de polipropileno respecto de las de malla metálica (Figura 6A).
En el mismo momento, se registró también un elevado porcentaje de plantines con el ápice seco, el $62 \%$ de plantines con protector TP y el 86\% con MM. En noviembre de 2010, se observaron daños por roedores pequeños (e.g., ratones) en algunas lengas que tenían protector de MM, como así también la presencia de cuevas de Ctenomys sp., conocido como tucutuco. La supervivencia disminuyó levemente el segundo año y se mantuvo similar todo el período de estudio. La diferencia en altura registrada en los plantines con distinto tipo de protector también se mantuvo (Figura 6A). Luego de 4 años, la supervivencia y altura promedio fueron $69 \%$ y $62 \%$, y 92 y $58 \mathrm{~cm}$ para los plantines protegidos con TP y MM, respectivamente (Figura 6A).

Monte Zeballos. La supervivencia promedio de los plantines en otoño de 2011, luego de la primera estación de crecimiento, fue $79 \%$, y se detectó un efecto marginal $(P=0.082)$ de los protectores en la supervivencia

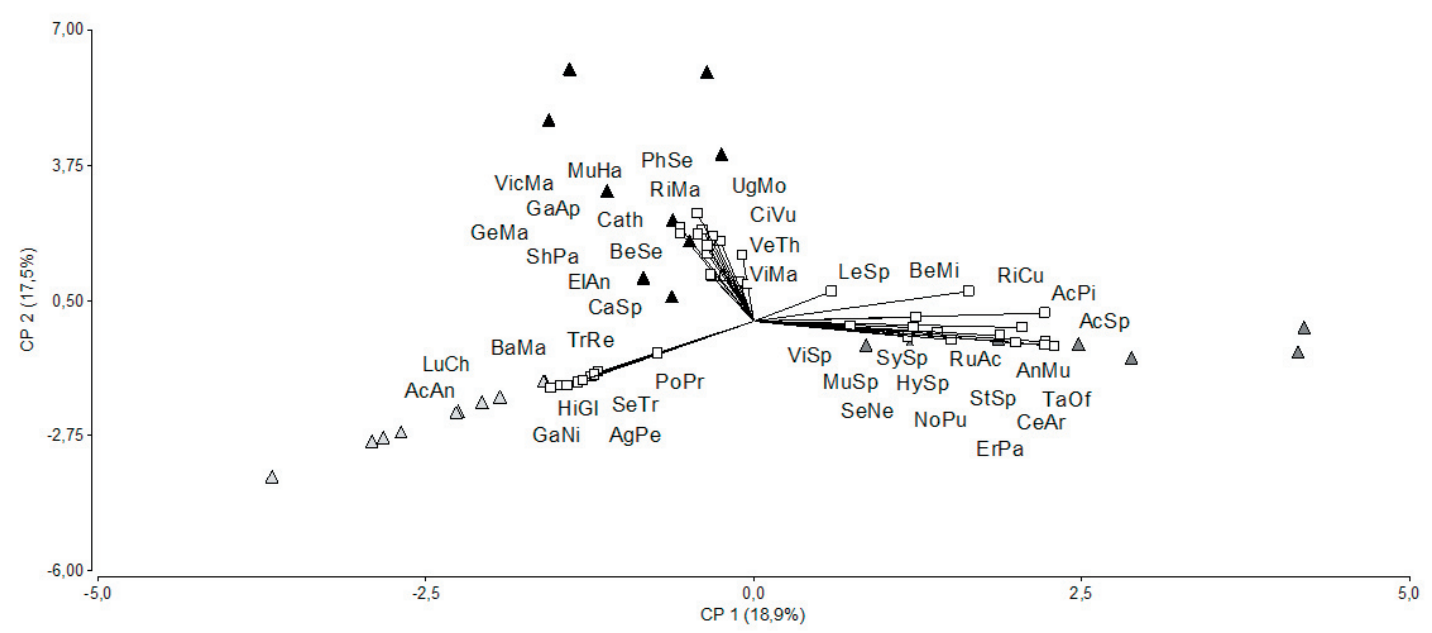

Figura 5. Gráfico biplot resultante del análisis de componentes principales, utilizando como variables las coberturas de las especies (cuadrados vacíos; nombres abreviados según Tabla 1). Los triángulos indican las parcelas por sitio: La Colisión=triángulos negros; Monte Zeballos=triángulos grises oscuro; Río Turbio=triángulos grises claro.

Figure 5. Biplot graph resulting from the PCA analysis using as a variables plant species cover (empty squares; species abbreviations according to Table 1). Triangles indicate plots corresponding to the three different sites. La Colisión=black squares; Monte Zeballos=dark grey squares; Río Turbio=light grey squares. 

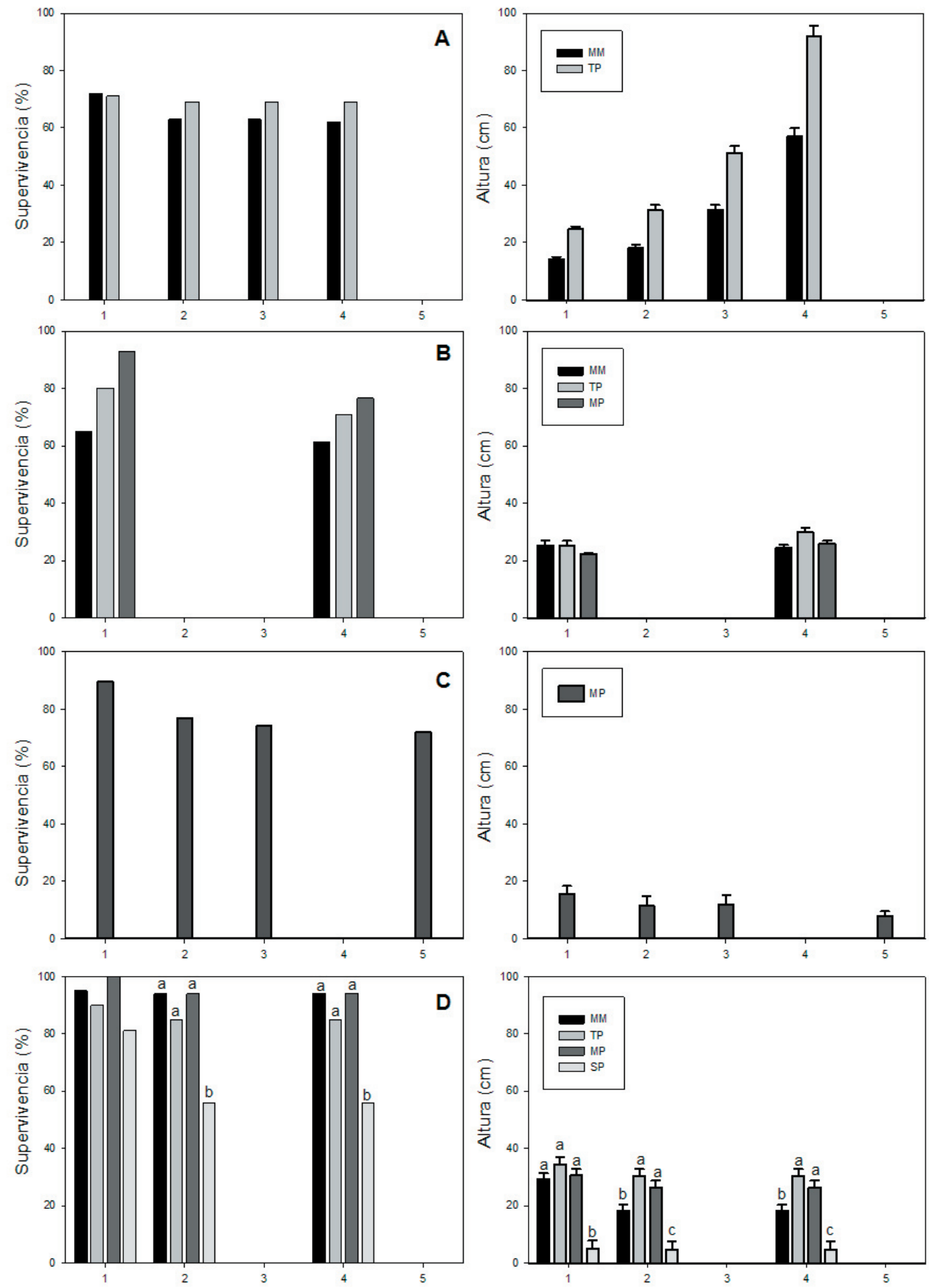

Estaciones de crecimiento post-plantación

Figura 6. Supervivencia de los plantines (izquierda) y altura media alcanzada (derecha) ( \pm EE) por ensayo y año de medición según el tipo de protección utilizada. A) La Colisión 2009: MM=malla metálica y TP=tubo de polipropileno; B) Monte Zeballos 2010: MM=malla metálica, TP=tubo de polipropileno y MP=malla de plástico; C) Río Turbio 2009: $\mathrm{MP}=$ malla de plástico y D) Río Turbio 2010: $\mathrm{MM}=$ malla metálica, $\mathrm{TP}=$ tubo de polipropileno, $\mathrm{MP}=$ malla de plástico y $\mathrm{SP}=$ sin protector. Letras diferentes indican diferencias significativas entre tipo de protectores $(P<0.05)$.

Figure 6. Seedling survival (left) and mean height $( \pm \mathrm{SE})$ achieved (right) at the end of each growing season and according to the type of protection used. A) La Colisión 2009: MM=metallic mesh, TP=polypropylene tube. B) Monte Zeballos 2010: $\mathrm{MM}=$ metallic mesh, $\mathrm{TP}=$ polypropylene tube and $\mathrm{PM=plastic}$ mesh. C) Río Turbio 2010: MM=metallic mesh, $\mathrm{TP}=$ polypropylene tube, $\mathrm{PM}=$ plastic mesh and $\mathrm{SP}=$ without protector. Different letters indicate significant differences among protection devices $(P<0.05)$. 
Tabla 3. Valores medios ( $\pm \mathrm{EE}$ ) de las variables analizadas en el bosque de lenga quemado y no quemado. Letras diferentes indican diferencias significativas en cada sitio. ${ }^{*} \mathrm{P}<0.05$, \# $\mathrm{P}<0.10$, ns: no significativo.

Table 3. Mean values $( \pm \mathrm{SE})$ of the variables analyzed in the burned and adjacent unburned lenga forests. Different letters indicate significant differences in each site. ${ }^{*} \mathrm{P}<0.05$, \# $\mathrm{P}<0.10$, ns: not significant.

\begin{tabular}{|c|c|c|c|c|c|c|c|c|c|}
\hline \multirow[b]{2}{*}{ Variable suelo } & \multicolumn{3}{|c|}{ La Colisión } & \multicolumn{3}{|c|}{ Monte Zeballos } & \multicolumn{3}{|c|}{ Río Turbio } \\
\hline & $\begin{array}{c}\text { No Quemado } \\
n=3\end{array}$ & $\begin{array}{l}\text { Quemado } \\
n=3\end{array}$ & $P$ & $\begin{array}{c}\text { No Quemado } \\
n=3\end{array}$ & $\begin{array}{c}\text { Quemado } \\
n=3\end{array}$ & $P$ & $\begin{array}{c}\text { No Quemado } \\
n=3\end{array}$ & $\begin{array}{l}\text { Quemado } \\
n=3\end{array}$ & $P$ \\
\hline pH agua 1:1 & $6.03 \pm 0.06 b$ & $6.77 \pm 0.11 \mathrm{a}$ & * & $5.84 \pm 0.42$ & $6.21 \pm 0.05$ & $\mathrm{~ns}$ & $6.03 \pm 0.18$ & $5.65 \pm 0.1$ & ns \\
\hline $\mathrm{CE}(\mathrm{dS} / \mathrm{m})$ & $0.20 \pm 0.03 a$ & $0.05 \pm 0.00 \mathrm{~b}$ & * & $0.07 \pm 0.00$ & $0.07 \pm 0.01$ & ns & $0.14 \pm 0.02 b$ & $0.47 \pm 0.08 \mathrm{a}$ & * \\
\hline$\% \mathrm{CO}$ & $16.67 \pm 2.67 \mathrm{a}$ & $5.67 \pm 0.33 b$ & * & $4.67 \pm 1.76$ & $4.33 \pm 0.33$ & ns & $8.00 \pm 1.00$ & $7.67 \pm 0.88$ & ns \\
\hline$\% \mathrm{~N}$ total & $1.35 \pm 0.36 \mathrm{a}$ & $0.43 \pm 0.11 b$ & * & $0.22 \pm 0.12$ & $0.28 \pm 0.01$ & ns & $0.32 \pm 0.08$ & $0.43 \pm 0.12$ & ns \\
\hline P disp. (mg/kg) & $139.7 \pm 13.0 \mathrm{a}$ & & * & & & ns & $.3 \pm 6.0 \mathrm{a}$ & 95.3 & $\#$ \\
\hline Relación C/N & $13.00 \pm 1.15$ & $16.67 \pm 6.23$ & ns & $27.33 \pm 8.09$ & $16.33 \pm 1.45$ & ns & $27.00 \pm 4.16$ & $20.67 \pm 5.70$ & ns \\
\hline $\mathrm{Ca}(\mathrm{meq} / 100 \mathrm{~g})$ & $29.07 \pm 3.73 a$ & $11.5 \pm 0.78 \mathrm{~b}$ & * & $8.70 \pm 1.24$ & $9.17 \pm 1.08$ & ns & $24.83 \pm 0.67$ & $25.43 \pm 1.75$ & ns \\
\hline $\mathrm{K}(\mathrm{meq} / 100 \mathrm{~g})$ & $1.67 \pm 0.22 \mathrm{a}$ & $0.40 \pm 0.00 \mathrm{~b}$ & * & $0.90 \pm 0.17$ & $0.70 \pm 0.12$ & ns & $1.30 \pm 0.06$ & $1.40 \pm 0.10$ & ns \\
\hline $\mathrm{Mg}(\mathrm{meq} / 100 \mathrm{~g})$ & $2.43 \pm 0.71 b$ & $5.53 \pm 0.75 a$ & * & $2.93 \pm 2.31$ & $3.57 \pm 1.22$ & ns & $1.87 \pm 1.32 b$ & $6.97 \pm 1.09 \mathrm{a}$ & * \\
\hline $\mathrm{Na}(\mathrm{meq} / 100 \mathrm{~g})$ & $2.97 \pm 1.20 \mathrm{a}$ & $0.33 \pm 0.19 b$ & $\#$ & $0.43 \pm 0.13 \mathrm{a}$ & $0.20 \pm 0.00 \mathrm{~b}$ & * & $0.67 \pm 0.03$ & $0.47 \pm 0.03$ & ns \\
\hline $\mathrm{CIC}(\mathrm{meq} / 100 \mathrm{~g})$ & $49.33 \pm 6.84 a$ & $36.67 \pm 4.26 \mathrm{~b}$ & $\#$ & $24.33 \pm 7.69$ & $23.67 \pm 1.76$ & ns & $47 \pm 3.00$ & $46 \pm 2.08$ & 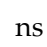 \\
\hline $\mathrm{S}-\mathrm{SO}_{4}(\mathrm{mg} / \mathrm{kg})$ & $56.33 \pm 2.19 b$ & $73.33 \pm 1.33 a$ & * & $42.00 \pm 11.02$ & $57.67 \pm 9.96$ & ns & $27 \pm 0.58 b$ & $82 \pm 5.29 a$ & $*$ \\
\hline
\end{tabular}

$(\mathrm{MP}>\mathrm{TP}>\mathrm{MM})$ (Figura 6B). El porcentaje de plantines con ápice seco varió el primer año entre los protectores, momento en que se registró $58 \%$ en $\mathrm{MM}, 71 \%$ en $\mathrm{TP}$ y $11 \%$ en MP. Al cuarto año, los plantines protegidos con MM y TP presentaron el mismo porcentaje de ápice seco que en el primer año, mientras que los plantines con MP aumentaron al $56 \%$. La supervivencia disminuyó levemente hacia el cuarto año, cuando no se detectaron diferencias entre protectores. La altura luego del primer y del cuarto año tampoco varió en relación al tipo de protector. Luego de 4 años, la supervivencia y altura promedio fueron $70 \%$ y $27 \mathrm{~cm}$, respectivamente (Figura 6B).

Río Turbio. En el ensayo de Río Turbio 2009, la supervivencia promedio de los plantines en otoño de 2010, luego de la primera estación de crecimiento, fue $90 \%$. La misma disminuyó levemente hacia el segundo año y se mantuvo en los años subsiguientes (Figura 6C). Luego del primer año se registró también un porcentaje elevado $(>60 \%)$ de plantines con ápice seco; la altura media fue $\sim 15 \mathrm{~cm}$, y disminuyó en los años posteriores (Figura $6 C)$.

En el ensayo de Río Turbio 2010, la supervivencia promedio de los plantines en otoño de 2011, luego de la primera estación de crecimiento, fue $95 \%$ y no varió según el tipo de protector. Al segundo y cuarto año, la supervivencia disminuyó levemente, lo que se asoció al tipo de protector, y fue significativamente mayor $(P<0.05)$ en los plantines con protectores respecto de aquellos sin protección $(\mathrm{MP}=\mathrm{TP}=\mathrm{MM}>\mathrm{SP}$ ) (Figura 6D). Luego del primer año, el porcentaje de plantines con ápice seco fue mayor a $60 \%$ y la altura fue diferente en los plantines sin protección respecto de los plantines con los tres tipos de protectores. Al segundo y cuarto año, la altura alcanzada también fue diferente $(P<0.05)$ según el tipo de protector $(\mathrm{TP}=\mathrm{MP}>\mathrm{MM}>\mathrm{SP})$ (Figura 6D). En este ensayo se observó, además del secamiento de ápices, el elevado daño ocasionado por las liebres, que afectó al $80 \%$ de los plantines, aún con protecciones individuales (Figura 7). Ambas condiciones condujeron a que la altura media de los plantines a partir del primer año fuera notablemente menor en comparación al momento del establecimiento del ensayo, y disminuyera con el paso de los años.

La supervivencia de la lenga al primer año en los distintos sitios no se correlacionó significativamente $(P>0.05)$ con ninguna de las variables de cobertura total y relativa estudiadas e indicadas en la Tabla 2. Tampoco con las propiedades físico-químicas del suelo analizadas e indicadas en la Tabla 3.

\section{Discusión}

\section{Cobertura y diversidad}

La cobertura total del suelo y la cobertura relativa según el hábito y el origen de las especies son diferentes entre los sitios analizados en este trabajo. En el bosque 

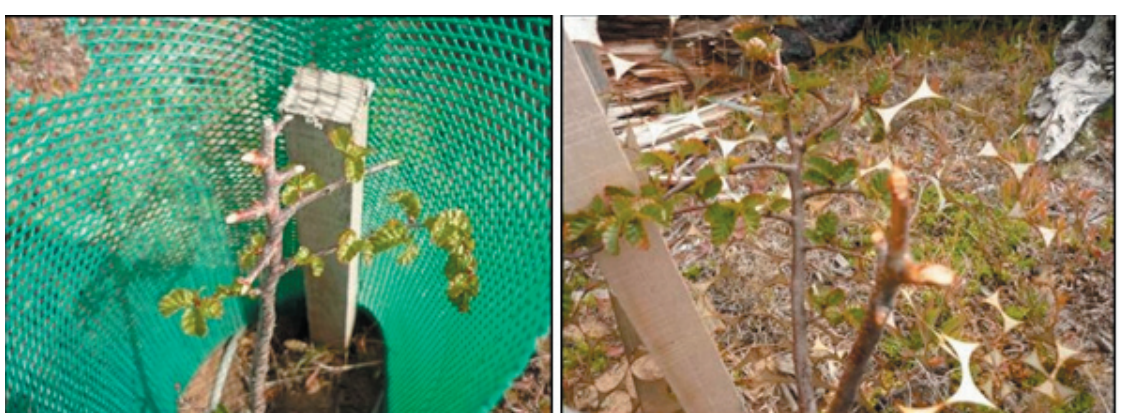

Figura 7. Imágenes de plantines de lenga dañados por liebre con protección individual. MP a la izquierda y MM a la derecha.

Figure 7. Photographs of lenga seedlings located within individual protectors showing the browsing effects caused by European hares. MP to the left and MM to the right. recientemente quemado $\mathrm{LC}$, la cobertura elevada de especies herbáceas y una fracción del suelo descubierto sin vegetación se corresponden con una etapa temprana de la sucesión post-fuego. Las especies Muehlenbeckia hastulata, Vicia magellanica y Phacelia secunda se presentan como características de esta etapa. Por las condiciones del sitio, LC podría continuar su trayectoria sucesional hacia un matorral post-fuego, siempre que se mantenga excluido el ganado. MZ y RT, afectados por fuegos antiguos y pastoreo, se corresponderían a estados de vegetación estable, transformados a pastizal como el caracterizado por Rusch (1989). La mayoría de las especies presentes (Acaena, Rumex, Geranium y Mulinum) en MZ, coinciden con las más conspicuas mencionadas por Rusch (1989) para pastizales post-fuego de bosque de lenga. Este sitio se presenta como el bosque quemado más deteriorado en función del alto porcentaje de suelo desnudo, como así también por la dominancia de Mulinum y Acaena, especies características de sitios degradados principalmente por sobrepastoreo (León and Aguiar 1985). En Río Turbio, si bien la cobertura de especies exóticas es similar a la de las nativas, Hieracium praealtum cubre un alto porcentaje del suelo y podría estar limitando el desarrollo de la regeneración de lenga al ocupar físicamente la superficie del suelo, tal como ocurre en bosques de la misma zona (Peri and Ormaechea 2013a). En LC y en MZ, la cobertura de especies exóticas es baja. La cobertura de estas especies en bosques quemados es muy variable (Varela et al. 2006; Blackhall et al. 2015) y estaría asociada al uso previo o posterior de las áreas quemadas, así como a la presencia de las especies exóticas en las áreas colindantes (Gobbi 1994).

La riqueza y el índice de diversidad de Shannon son similares en los tres bosques quemados estudiados, y también se asemejan a bosques de lenga afectados por fuego en el noroeste de su distribución (Varela et al. 2006). Estos valores también son similares a bosques de lenga sometidos a uso pastoril en Chubut y en Tierra del Fuego, donde encuentran mayor riqueza a menor latitud (Quinteros et al. 2012). Sin embargo, los sitios quemados estudiados presentan mayor riqueza y diversidad que los determinados en bosques altos, con y sin aprovechamiento forestal (Silva et al. 2017).

\section{Propiedades del suelo}

Bosque no quemado o verde. Los suelos de los sitios con bosque sin quemar muestran características de los suelos Andisoles, que presentan, en general, bajo grado de desarrollo (Poudel and West 1999). Estos suelos se desarrollan sobre una sucesión de capas de cenizas volcánicas y piroclastos de tipo andesítico (Etchevehere 1972). Las cenizas volcánicas son coherentes, menos susceptibles a los transportes eólicos, y son capaces de sostener una vegetación boscosa como los bosques de lenga (Irisarri and Mendía 1997). Asimismo, las arcillas amorfas como el alófano brindan una gran capacidad de retención hídrica, alta porosidad, elevada capacidad de intercambio catiónico/aniónico, alta superficie específica y baja densidad aparente (Irisarri and Mendía 1997). La Colisión muestra mayor contenido de carbono orgánico y de nitrógeno, similar a bosques de Nothofagus próximos al área, así como a otros bosques de lenga ubicados más al norte de la distribución (Alauzis et al. 2004). RT presenta un valor intermedio de carbono, mientas que MZ presenta el menor valor. En general, los valores más altos corresponden a alófanos bien definidos y los más bajos a zonas transicionales (Colmet Dâage et al. 1993). Los tres sitios presentan $\mathrm{pH}$ ligeramente ácido, alta disponibilidad de fósforo y buena capacidad de intercambio catiónico.

Bosques quemados. Los cambios en las propiedades del suelo detectados en LC, tales como el incremento del pH y la disminución de la mayoría de las variables consideradas en 
relación con el sector no quemado, se asocian principalmente a la combustión de la materia orgánica del suelo, que tiene un rol clave en el ciclo de nutrientes, el intercambio de cationes y la retención de agua. En bosques de lenga y también de Nothofagus glauca, los cambios detectados durante los primeros años luego del fuego también se relacionaron principalmente con la combustión/oxidación de la capa superficial del suelo (horizonte A) y, posteriormente, con los cambios simultáneos en el ambiente (e.g., reducción en el contenido de materia orgánica, disminución de la humedad y aumento del $\mathrm{pH}$ del suelo) (Litton and Santelices 2003; Alauzis et al. 2004). En esos trabajos se registró también un aumento del fósforo intercambiable inmediatamente después del incendio, que permaneció en valores significativamente más altos que en el sector no quemado durante los años de estudio. A diferencia de esos estudios, en LC, el fósforo disponible es menor en el sector quemado. La respuesta del fósforo disponible luego del fuego es variable y más difícil de predecir que los otros nutrientes (Raison 1979). La severidad del fuego puede afectar los cambios en el fósforo disponible. Durante fuegos de alta severidad, de $50 \%$ a $60 \%$ del total del fósforo combustible puede perderse por volatilización (DeBano 1991). Asimismo, el fuego también afecta la actividad enzimática y la mineralización del fósforo (DeBano and Klopatek 1988).

En RT y MZ, el contenido de carbono y de nitrógeno en los sectores quemados es similar al contenido en el bosque no quemado, por lo que se estima que se han recuperado luego del fuego. En estos sitios sería importante dilucidar si, transcurridos muchos años desde el incendio, los cambios detectados (especialmente en fósforo, magnesio y azufre en RT), se relacionan al efecto "fuego" o al uso ganadero posterior al mismo. En general, después de ocurrido el incendio, los cambios en las propiedades del suelo son mayores en la capa de $0-5 \mathrm{~cm}$ de profundidad y más modestos en la de $5-10 \mathrm{~cm}$.

\section{Restauración activa}

La supervivencia de los plantines de lenga es alta en todos los sitios, independiente de las características morfológicas, de la edad de viverización de los mismos (Urretavizcaya et al. 2013) y de los dispositivos de protección probados. Asimismo, y considerando el período de estudio, no se detecta un efecto particular asociado a la diferencia entre los sitios de trabajo. Distintas experiencias de plantación en bosques quemados de lenga en la región también mostraron buena supervivencia inicial (Gobbi et al. 2008; Martucci 2010; Mondino 2014). Esos estudios analizan factores como exposición de ladera, especies nodrizas y protección para evitar el daño por liebres, y también la presencia de caña colihue (Chusquea culeou). Otras experiencias, sin embargo, reportaron supervivencias menores en ensayos de aplicación de mulch (Lallement et al. 2010). En este trabajo se observa, además, una alta frecuencia de ápices secos en todos los sitios. En bosques naturales, la muerte de brotes anuales en especies de Nothofagus es un evento frecuente. La lenga presenta muerte de ápices en todos los estadios: plántula, renoval, árbol juvenil, árbol adulto y árbol reiterado (Stecconi 2006). Las causas de la muerte podrían ser tanto exógenas (por efecto del ambiente) como endógenas (con base genética); sin embargo, resulta muy difícil diferenciar entre ambos orígenes (Stecconi 2006). También se ha registrado la muerte frecuente de brotes anuales en plantaciones de roble pellín (Nothofagus=Lophozonia obliqua) (Davel et al. 2004).

En LC, las lengas protegidas por el tubo de polipropileno (TP) crecen más que las protegidas con malla metálica (MM); esto puede asociarse a que el TP, por ser una lámina cerrada, pudo haber protegido a los plantines del viento. Los individuos de Nothofagus sometidos a fuertes vientos, como los que se registran en extensas áreas quemadas, pueden mostrar una reducción en el crecimiento primario (Stecconi 2006). Distintos trabajos demuestran que este tipo de protectores produce, dentro del mismo, una mejora en las condiciones micro-ambientales que beneficia a los plantines (Dubois et al. 2000; Chaar et al. 2008; Urretavizcaya and Defossé 2013). Por el contrario, los protectores metálicos no generarían ningún cambio microambiental favorable para el plantín (Gobbi et al. 2008). En este sitio, los plantines con TP crecen en promedio $18 \mathrm{~cm} / \mathrm{año}$, mientras que los protegidos con MM, $8 \mathrm{~cm} /$ año. Otras experiencias realizadas en bosques quemados cercanos a LC, en la provincia de Chubut, indican crecimientos iniciales medios de 6.3 cm (Mondino 2014). Se observa, además, daño por ratones durante el primer año, que afecta a los plantines, aunque sin provocar su muerte. El ramoneo ocasional presenta los 
mismos efectos que un traumatismo puntual, en que algún eje cercano a la parte cortada se diferencia y reemplaza al eje dañado (Stecconi 2006).

En MZ 2010 y en RT 2009, el escaso o nulo crecimiento de las lengas, junto a la alta frecuencia de secamiento de ápices, podría relacionarse tanto a factores ambientales del sitio como a factores genéticos vinculados a la procedencia de las semillas del material de reproducción utilizado. La falta de cobertura de un dosel de protección y la exposición al viento son condiciones ambientales severas que pueden haber afectado el crecimiento. Asimismo, la baja fertilidad y el alto porcentaje de suelo desnudo en $\mathrm{MZ}$, y la alta cobertura de suelo con especies gramíneas y de Hieracium en RT, pueden haber limitado el crecimiento de la lenga. Mientras que en el bosque nativo Hieracium restringe la instalación de plántulas por una ocupación física (Peri and Ormaechea 2013a), en la restauración realizada en RT es altamente probable que, debido a su abundancia y a su sistema radical muy desarrollado, limite el establecimiento de los plantines de lenga compitiendo por el agua. Respecto al sitio de procedencia del material de reproducción, el mismo registra una precipitación superior a $900 \mathrm{~mm} / \mathrm{año} \mathrm{y}$ se ubica a $\sim 350$ y $900 \mathrm{~km}$ al norte de MZ y de RT, respectivamente. Si bien los plantines presentan muy buena supervivencia, luego de 4 años, el crecimiento es escaso. Al elegir el material de plantación se debe considerar la adaptación al sitio del acervo genético (origen) que se utiliza, lo que se traducirá no solo en la supervivencia de los plantines sino también en su desempeño general. La mala adaptación de un genotipo expuesto a un determinado ambiente puede reflejarse en un fenotipo de crecimiento escaso $y$, consecuentemente, poca capacidad competitiva (Pastorino et al. 2015). En Río Turbio 2010, si bien se registra buena supervivencia de los plantines con protección, la altura de los mismos es afectada por el daño severo ocasionado por las liebres, aún por encima de las protecciones, que limitó significativamente el desarrollo de las lengas.

Para bosques de lenga del noroeste de la Patagonia argentina afectados por fuegos intensos en pequeños parches se ha sugerido que la productividad post-fuego y la regeneración estarían relacionadas con los cambios edáficos, en especial aquellos que afectan la dinámica del nitrógeno y el agua (Alauzis et al. 2004). Asimismo, otros autores encontraron que el fuego reciente y la herbivoría de ganado vacuno, actuando en combinación, disminuyeron la cobertura de especies leñosas y semi-leñosas y redujeron la disponibilidad de micro-sitios que facilitan el establecimiento de especies. La reducción de la biomasa debida al fuego y al efecto directo e indirecto de los herbívoros puede cambiar las condiciones micro-ambientales y condicionar el establecimiento de la regeneración natural (Blackhallet al.2015). En este trabajo, los valores de supervivencia en plantación a un año del fuego, así como en los posteriores, indicarían que la regeneración en el corto plazo no estaría controlada por los cambios de fertilidad del suelo sino por una conjunción de factores entre los que la disponibilidad de semillas y la protección de plántulas contra herbívoros serían relevantes. En los sitios con mayor antigüedad de quemado, como $\mathrm{MZ}$ y RT, que presentan propiedades de suelo similares al bosque sin quemar, la falta de semillas es una limitante substancial pero el tipo y porcentaje de la cobertura del suelo también serían explicativos. Esta puede ser muy baja o muy alta como en MZ o RT, respectivamente. En el caso de que la disponibilidad de semillas no sea limitante, el suelo desnudo como en Monte Zeballos puede alcanzar altas temperaturas y suscitar la deshidratación de las plántulas luego de germinar. En ese caso, las especies Mulinum y Acaena pueden brindar micro-sitios favorables para el establecimiento inicial de la lenga, tal como ha sido observado en otras especies arbóreas como Austrocedrus chilensis (Rost 2016). En RT, la presencia de "empastado" no permitiría el anclaje de las semillas germinadas en el suelo y, por ende, la supervivencia de las plántulas de regeneración natural sería reducida. Se suma a ello el daño que producen los pequeños herbívoros como las liebres, que en estos sitios muestran un efecto negativo muy significativo.

En zonas quemadas y con presencia de ganado, la mortalidad del dosel arbóreo y la herbivoría interactúan en forma sinérgica, lo que disminuye de manera significativa la posibilidad de regeneración natural del bosque (Raffaele et al. 2011). En estos casos, la restauración activa mediante plantación es una alternativa viable siempre que se puedan proteger a los plantines, realizar algún control/disminución de la población de liebres y avanzar en la definición de las zonas de procedencia de material genético para que, además de buena supervivencia las plantas muestren un adecuado desarrollo con relación al sitio de establecimiento. 
Agradecimientos. Agradecemos a los propietarios de los predios donde se realizaron los estudios. A la Ing. Florencia Deccechis por su colaboración, así como a los técnicos y brigadistas que participaron en distintas instancias del proyecto. Gracias a Melisa Rago, Ivonne Orellana y Pamela Quinteros por su colaboración en el análisis de datos de cobertura y riqueza. También a María Laura Besio por la revisión del texto. Agradecemos además los comentarios y sugerencias de los dos revisores que nos permitieron mejorar la primera versión del manuscrito. Este trabajo forma parte del Proyecto PICTO 36663: "Restauración ecológica en bosques degradados de la Patagonia andina de Chubut y Santa Cruz: aspectos básicos y desarrollo de tecnologías", realizado con un subsidio de la Agencia Nacional de Promoción Científica y Tecnológica de Argentina.

\section{REFERENCIAS}

Alauzis, M. V., M. J. Mazzarino, E. Raffaele, and L. Roselli. 2004. Wildfires in NW Patagonia: long-term effects on a Nothofagus forest soil. Forest Ecology and Management 192:131-142.

Bava, J. O., J. D. Lencinas, and A. Haag. 2006. Determinación de la materia prima disponible para proyectos de inversión forestales en cuencas de la provincia del Chubut. Consejo Federal de Inversiones, Provincia del Chubut, Esquel.

Black, C. A. 1965. Methods of Soil Analysis Part 2, Madison WI, USA.

Blackhall, M., E. Raffaele, and T. T. Veblen. 2015. Efectos combinados del fuego y el ganado en matorrales y bosques del noroeste patagónico. Ecología Austral 25:1-10.

Bray, R. H., and L. Kurtz. 1945. Determination of total, organic, and available forms of phosphorus in soils. Soil science 59:39-46.

Bremner, J. 1960. Determination of nitrogen in soil by the Kjeldahl method. The Journal of Agricultural Science 55: 11-33.

Cabrera, A. L. 1976. Las Regiones Fitogeográficas Argentinas. Editorial ACME, Buenos Aires.

CIEFAP, and MAyDS. 2016. Actualización de la Clasificación de Tipos Forestales y Cobertura del Suelo de la Región Bosque Andino Patagónico. Informe Final CIEFAP, URL: goo.gl/5pGauJ.

Colmet Dâage, F., M. J. Mazzarino, and A. A. Lanciotti. 1993. Características de los suelos volcánicos en el S.O. del Chubut. INTA. EEA, Bariloche.

Colwell, R. 2013. EstimateS: Statistical estimation of richness and shared species from samples. Version 9. User's guide and application. URL: purl.oclc.org.

Correa, M. 1969-1988. Flora Patagónica I-VIII. Colección Científica INTA. Buenos Aires. Argentina.

Chaar, H., T. Mechergui, A. Khouaja, and H. Abid. 2008. Effects of treeshelters and polyethylene mulch sheets on survival and growth of cork oak (Quercus suber L.) seedlings planted in northwestern Tunisia. Forest Ecology and Management 256: 722-731.

Davel, M., M. F. Urretavizcaya, L. Contardi, and G. De María. 2004. Establecimiento y plantación de especies nativas de madera de calidad en el noroeste de la provincia del Chubut. Pp. 25-30 in C. A. Norverto (ed.). Investigación forestal al servicio de la Producción II. Resultados aplicables al cultivo de bosques y la producción de madera en Argentina. Proyecto Forestal de Desarrollo, Secretaría de Agricultura, Ganadería, Pesca y Alimentos, Buenos Aires.

Davies, B. E. 1974. Loss-on-ignition as an estimate of soil organic matter. Soil Science Society of American Journal 38: 150-151.

DeBano, L. F. 1991. The effect of fire on soil properties. Pp. 151-155 in Proceedings management and productivity of western-Montane Forest Soils, Boise, ID.

DeBano, L. F., and J. M. Klopatek. 1988. Phosphorus dynamics of pinyon-juniper soils following simulated burning. Soil Science Society of America Journal 52:271-277.

Dubois, M. R., A. H. Chappelka, E. Robbins, G. Somers, and K. Baker. 2000. Tree shelters and weed control: Effects on protection, survival and growth of cherrybark oak seedlings planted on a cutover site. New Forests 20:105-118.

Ehrenfeld, J. G. 2000. Defining the limits of restoration: the need for realistic goals. Restoration Ecology 8:2-9.

Etchevehere, P. H. 1972. Los suelos de la Región Andino Patagónica. Pp. $83-95$ in M. J. Dimitri (ed.). La Región de los Bosques Andino-Patagónicos, Sinopsis General. Colección Científica del INTA, Buenos Aires, Argentina.

Gobbi, M., S. Varela, and R. Pablos. 2008. Plantación de Nothofagus pumilio como técnica de recuperación post incendio. Pp. 165-169 in Segunda reunión sobre Nothofagus en patagonia-EcoNothofagus 2008. CIEFAP-CFI-UNSJB-UNCUACH, Esquel.

Gobbi, M. E. 1994. Regeneración de la vegetación en incendios recientes de bosques de -ciprés de la cordillera(Austrocedrus chilensis) en áreas del Parque Nacional. Medio Ambiente 12:9-15.

Grubb, P. J. 1977. The maintenance of species』richness in plant communities: the importance of the regeneration niche. Biological reviews 52:107-145.

Hurlbert, S. H. 1984. Pseudoreplication and the design of ecological field experiments. Ecological Monographs 54: 187-211.

Irisarri, J., and J. Mendía. 1997. Relaciones suelo-paisaje en la evaluación de la potencialidad forestal de la región central andino-patagónica, Argentina. Bosque 18:21-30. 
Jiménez-Valverde, A., and J. Hortal. 2003. Las curvas de acumulación de especies y la necesidad de evaluar la calidad de los inventarios biológicos. Revista Ibérica de Aracnología 8:151-161.

Kalela, E. 1941. On the tree species and the successional changes in the composition, caused by climatic conditions, in the forests of E. Patagonia. Suomalaisen Tiedeakatemian Toimituksia, Helsinki (Ser. A) IV. Biologica.

Kitzberger, T., E. Raffaele, K. Heinemann, and M. J. Mazzarino. 2005a. Effects of fire severity in a north Patagonian subalpine forest. Journal of Vegetation Science 16:5-12.

Kitzberger, T., E. Raffaele, and T. T. Veblen. 2005b. Variable community responses to herbivory in fire-altered landscapes of northern Patagonia, Argentina. African Journal of Range and Forage Science 22(2):85-91.

Lallement, M., C. Tognetti, and M. E. Gobbi. 2010. Post-fire restoration of native tree species: effects of wood shaving application. Pp. 154-156 in A. Newton and N. Tejedor (eds.). Principles and Practice of Forest Landscape Restoration. Case studies from the drylands of Latin America. IUCN, Gland, Switzerland and Cambridge, UK.

León, R. J. C., and M. R. Aguiar. 1985. El deterioro por uso pasturil en las estepas herbáceas patagónicas. Phytocoenología 13:181-196.

Litton, C. M., and R. Santelices. 2003. Effect of wildfire on soil physical and chemical properties in a Nothofagus glauca forest, Chile. Revista Chilena de Historia Natural 76:529-542.

López Bernal, P. M., M. F. Urretavizcaya, and G. E. Defossé. 2012. Seedling Dynamics in an Environmental Gradient of Andean Patagonia, Argentina. Pp. 189-210 in C. Busso (ed.). From seed germination to young plants: ecology, growth and environmental influences. Nova Science Publishers, Inc., New York, USA.

Martucci, A. A. 2010. Ensayo de plantación de lenga (Nothofagus pumilio) en un bosque quemado. Universidad Nacional de la Patagonia, Esquel.

Mondino, V. 2014. Variación geográfica y genética en caracteres adaptativos iniciales de Nothofagus pumilio (Poepp. et Endl.) Krasser en una zona de alta heterogeneidad ambiental. Tesis de Doctorado. UBA, Buenos Aires.

Pastorino, M., A. Aparicio, and M. M. Azpilicueta. 2015. Regiones de Procedencia del Ciprés de la Cordillera y bases conceptuales para el manejo de sus recursos genéticos en Argentina. Ediciones INTA, Buenos Aires.

Peri, P., and S. Ormaechea. 2013a. Especies invasoras exóticas en ñirantales de Santa Cruz: Hieracium praealtum e Hypochoeris radicata. Pp. 103 in P. Peri (ed.). II Jornadas Forestales de Patagonia Sur y $2^{\text {do }}$ Congreso Internacional Agroforestal Patagónico INTA-Instituto Forestal de Chile-UNPA-CONICET, El Calafate, Santa Cruz.

Peri, P. L. 2003. Planeamiento para la restauración de las áreas degradadas de bosque nativo de Nothofagus, perteneciente al ejido de la municipalidad de Río Turbio. 27.

Peri, P. L., and S. Ormaechea. 2013b. Relevamiento de los bosques nativos de ñire (Nothofagus antarctica) en Santa Cruz: base para su conservación y manejo. Presidencia de la Nación, Ministerio de Agricultura, Ganadería y Pesca.

Poudel, D., and L. West. 1999. Soil development and fertility characteristics of a volcanic slope in Mindanao, the Philippines. Soil Science Society of America Journal 63:1258-1273.

Quinteros, C. P. 2014. Grandes herbívoros en bosques de lenga (Nothofagus pumilio): uso espacio-temporal de los recursos y sus efectos sobre la regeneración y el sotobosque. Tesis de Doctorado. Universidad Nacional del Comahue, Bariloche.

Quinteros, C. P., P. M. L. Bernal, M. E. Gobbi, and J. O. Bava. 2012. Distance to flood meadows as a predictor of use of Nothofagus pumilio forest by livestock and resulting impact, in Patagonia, Argentina. Agroforestry Systems 84: 261-272.

Quiroz, I., E. García R., M. González O., P. Chung Guin-Po, and H. Soto G. 2009. Vivero Forestal: Producción de plantas nativas a raíz cubierta. Instituto Forestal (INFOR) Concepción, Chile.

Raffaele, E., T. T. Veblen, M. Blackhall, and N. TerceronBucardo. 2011. Synergistic influences of introduced herbivores and fire on vegetation change in northern Patagonia, Argentina. Journal of Vegetation Science 22:59-71.

Raison, R. J. 1979. Modification of the soil environment by vegetation fires, with particular reference to nitrogen transformations: a review. Plant and Soil 51:73-108.

Richter, M., M. Conti, and G. Maccarini. 1982. Mejoras en la determinación de cationes intercambiables y capacidad de intercambio catiónico en los suelos. Revista de la Facultad de Agronomia 3:145-155.

Rost, E. I. 2016. Expansión de un relicto de ciprés en el ecotono chubutense durante dos décadas. Universidad Nacional de la Patagonia, Esquel.

Rusch, V. 1987. Estudio sobre la regeneración de la lenga (Nothofagus pumilio) en la cuenca del Río Manso Superior, Río Negro. Pp. 113 en Informe Final Beca de Iniciación. CONICET, Bariloche.

Rusch, V. 1989. Determinación de las transiciones de estado en bosques de lenga (Nothofagus pumilio). Page 76. CONICET, Bariloche.

Schollenberger, C., and R. Simon. 1945. Determination of exchange capacity and exchangeable bases in soil - ammonium acetate method. Soil Science 59:13-24.

SER. 2004. The SER International Primer on Ecological Restoration. Society for Ecological Restoration Tucson, Arizona, USA.

Silva, P. V., C. P. Quinteros, A. G. Greslebin, J. O. Bava, and G. E. Defossé. 2017. Characterization of Nothofagus pumilio (Lenga) Understory in Managed and Unmanaged Forests of Central Patagonia, Argentina. Forest Science 63:173-183.

Stecconi, M. 2006. Variabilidad arquitectural de especies nativas de Nothofagus de la Patagonia (N. antartica, N. pumilio, N. dombeyi). Tesis de Doctorado. Universidad Nacional del Comahue, Bariloche. 
Urretavizcaya, M. F., L. T. Contardi, M. F. Oyharçabal, and A. Christianse. 2013. Evaluación morfo-fisiológica de plantines de Nothofagus pumilio utilizados en la restauración ecológica de bosques quemados. Pp. 18 en II Jornadas Forestales de Patagonia Sur. INTA, Calafate, Argentina.

Urretavizcaya, M. F., and G. Defossé. 2013. Effects of nurse shrubs and tree shelters on the survival and growth of two Austrocedrus chilensis seedling types in a forest restoration trial in semiarid Patagonia, Argentina. Annals of Forest Science 70:21-30.

Varela, S. A., M. E. Gobbi, and F. Laos. 2006. Banco de semillas de un bosque quemado de Nothofagus pumilio: efecto de la aplicación de compost de biosólidos. Ecología Austral 16:63-78.

Veblen, T. T., C. Donoso, T. Kitzberger, and A. J. Rebertus. 1996. Ecology of southern Chilean and southern Argentinean Nothofagus forests. Pp. 293-353 in T. Veblen, R. S. Hill and J. Read (eds.). The ecology and biogeography of Nothofagus forests. Yale University Press New Haven and London.

Zuloaga, F., O. Morrone, and M. Belgrano. 2009. Flora del Cono Sur. Catálogo de las Plantas Vasculares in B. A. Instituto de Botánica Darwinion (ed.). URL: www.floraargentina.edu.ar. 